\title{
COACHING STYLES AND THE BASIC PSYCHOLOGICAL NEED FULFILLMENT OF COLLEGE ATHLETES
}

\author{
A Thesis \\ Presented to \\ the Faculty of California Polytechnic State University, \\ San Luis Obispo \\ In Partial Fulfillment \\ of the Requirements for the Degree \\ Master of Science in Agriculture, with Specialization in \\ Recreation, Parks and Tourism Management
}

by

Kelsey Louise Byrd

June 2018 
(C) 2018

Kelsey Louise Byrd

ALL RIGHTS RESERVED 


\section{COMMITTEE MEMBERSHIP}

TITLE:

Coaching Styles and the Basic

Psychological Need Fulfillment of College Athletes

AUTHOR:

Kelsey Louise Byrd

DATE SUBMITTED:

June 2018

COMMITTEE CHAIR: $\quad$ Brian Greenwood, Ph.D.

Associate Professor of Experience Industry Management

COMMITTEE MEMBER: Kelly Bodwin, Ph.D.

Assistant Professor of Statistics

COMMITTEE MEMBER: $\quad$ Stefanee Maurice, M.A.

Lecturer of Kinesiology 


\begin{abstract}
Coaching Styles and the Basic Psychological Need Fulfillment of College Athletes Kelsey Louise Byrd
\end{abstract}

The purpose of this study was to determine to what extent a coach's coaching style is associated with the athlete's basic psychological needs fulfillment of autonomy, competence and relatedness. A survey was distributed to 204 varsity student-athletes at Cal Poly, San Luis Obispo representing 13 teams. The data were used to determine the impact of coaching style on the athlete's fulfillment of autonomy, competence and relatedness. An authoritative head coaching style was found to have a positive impact on an athlete's fulfillment of autonomy, competence and relatedness. A similar result was found for assistant coaches. Overall, these findings can help coaches and athletic departments.

Keywords: coaching style, Baumrind's parenting style, self determination theory, basic needs, college athletes, autonomy, competence, relatedness 


\section{ACKNOWLEDGMENTS}

The author would like to thank Dr. Brian Greenwood, Dr. Kelly Bodwin and Stefanee Maurice, M.A. for their guidance and encouragement. In addition, the author would like to thank Dr. Susan Houge Mackenzie and Dr. Jens Omli for their guidance and support in the beginning stages of this idea. Also, the Cal Poly athletic director, Don Oberhelman, and all the coaches who allowed me to work with their student athletes. Finally, special thanks to my family and friends for their support and patience. 


\section{TABLE OF CONTENTS}

\section{Page}

LIST OF TABLES ............................................................. vii

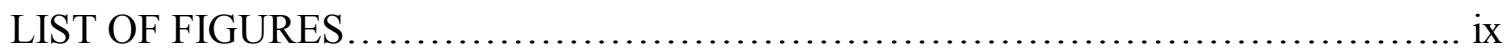

\section{CHAPTER}

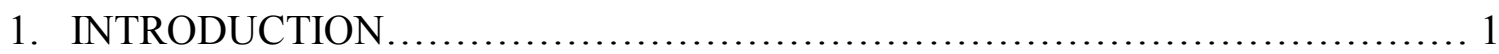

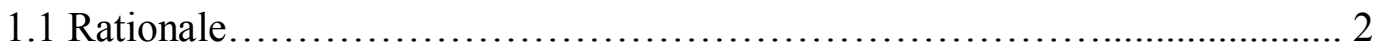

1.2 Purpose of the Study............................................. 3

1.3 Research Question.............................................. 3

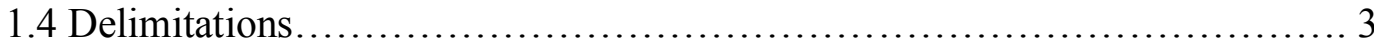

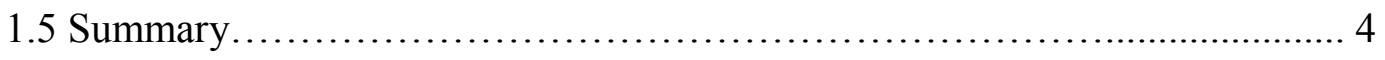

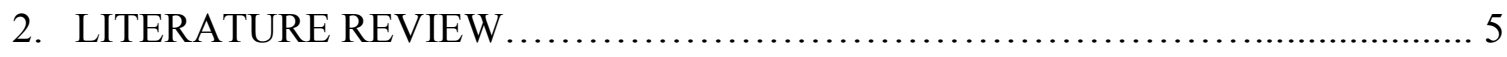

2.1 Self-Determination Basic Needs Theory $\ldots \ldots \ldots \ldots \ldots \ldots \ldots \ldots \ldots \ldots \ldots \ldots \ldots \ldots$

2.1.1 Relatedness........................................... 5

2.1.2 Competence............................................ 5

2.1 .3 Autonomy............................................... 6

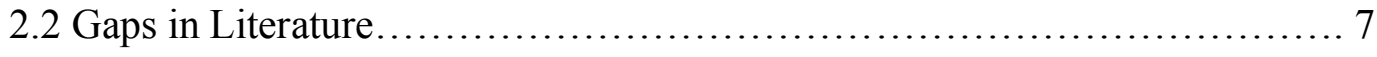

2.3 Baumrind's Parenting Model...................................... 8

2.3.1 Neglectful............................................... 8

2.3.2 Permissive................................................. 8

2.3.3 Authoritarian.......................................... 9

2.3.4 Authoritative.......................................... 10 
2.4 Area of Exploration................................................... 11

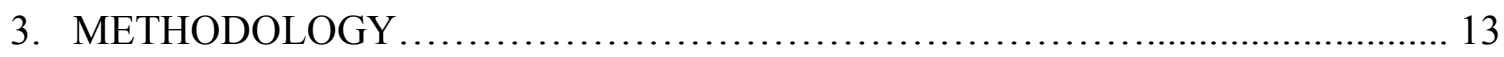

3.1 Study Locale ........................................................... 13

3.2 Description of Subjects.............................................. 13

3.3 Description of Instruments................................................. 13

3.3.1 Basic Needs Fulfillment...................................... 13

3.3.2 Baumrind's Coaching Style................................. 13

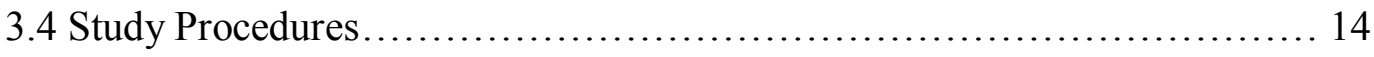

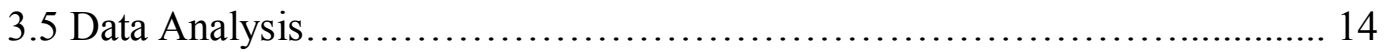

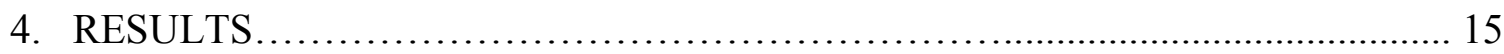

4.1 Respondent Demographics........................................ 15

4.2 Linear Mixed Model Regression......................................... 20

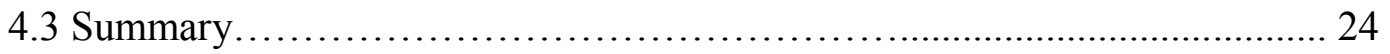

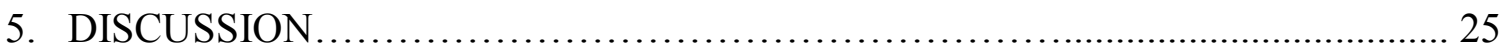

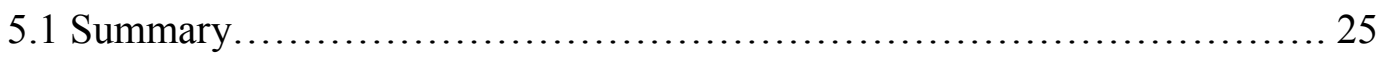

5.2 Discussion and Practical Implications................................. 26

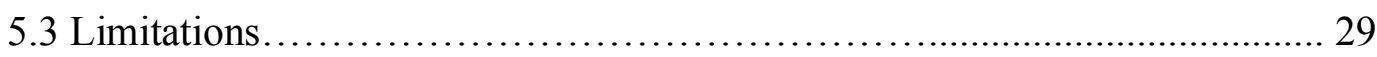

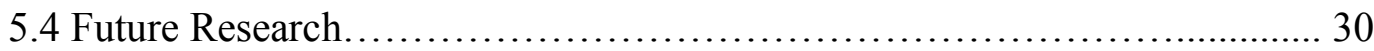

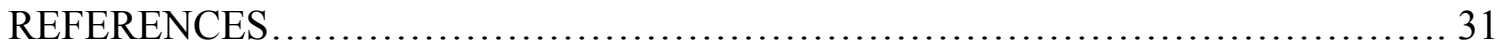

\section{APPENDICES}

A. Basic Needs Satisfaction in Sport Scale Survey ......................... 35

B. Adapted Parental Authority Questionnaire............................... 38 


\section{LIST OF TABLES}

Table Page

1. Mean and Standard Deviation of Coaching Styles of Head Coaches.................... 16

2. Mean and Standard Deviation of Coaching Styles of Assistant Coaches.................. 16

3. Multivariate ANOVA for Head Coaches and Assistant Coaches.......................... 17

4. Mean and Standard Deviation of Athletes' Basic Needs............................... 18

5. Multivariate ANOVA for Athletes' Basic Needs...................................... 18

6. Basic Needs Satisfaction by Gender of Athlete...................................... 19

7. Basic Needs Satisfaction by Team Type....................................... 19

8. Summary of Linear Regression for Head Coach's Coaching Style Predicting Basic Needs.

9. Summary of Linear Regression for Assistant Coach's Coaching Style Predicting Basic Needs 


\section{LIST OF FIGURES}

Figure

Page

1. Box Plot of Each Head Coach's Authoritative Coaching Style Score.................. 17

2. Visual Representation of Linear Mixed Method Regression Equation................ 23 


\section{CHAPTER 1}

\section{INTRODUCTION}

Athletics is a large part of life for many youth. An estimated eight million high school students in the United States participate in high school athletics each year (NCAA, 2017). From those eight million only $7 \%$ compete in their sport in college and an even smaller percent compete at the Division 1 level (NCAA, 2017). The students who compete at the college level spend on average 20 hours a week training and practicing in their respective sports, equivalent to a part time job. In college, athletes spend more time with their coaches than any other adult. College coaches have a significant impact on their athletes, whether positive or negative.

Many studies that focus on the impact of coaches on athletes focus on youth sports. Coaches in youth sports have a large impact on the development of youth into adults and, therefore, rightfully a lot of attention is paid to this age group. However, it can be argued that the impact of college coaches should also be looked at closely, as they are shaping young adults into independent adults.

College sports create a unique environment that differs from youth sports. In the college environment, coaches are employed based on their ability to win games and, therefore, the pressure to produce results is high. As a result, many coaching practices that would seem inappropriate or extreme for youth sports are prominent in college sports. These more extreme practices have come under fire lately with a number of former players filing verbal and physical abuse lawsuits against their college coaches. The rise in lawsuits has made college coaches aware of their actions and led to some changes in the prominent coaching style being employed 
in college sports. As coaching styles become more important to college administrations, a study of coaching styles is relevant and important to the field.

\section{$\underline{1.1 \text { Rationale }}$}

With the understanding that college coaches tend to be more demanding and potentially more controlling than youth sports, it is important to understand the psychological and motivational impact on college athletes. The basic needs sub-theory of self determination theory lays out three psychological needs that all individuals seek to fulfill in their lives: autonomy, competence and relatedness (Ryan \& Deci, 2000). An individual's needs can be supported or thwarted by the environment they spend time in. For a college athlete who spends at least 20 hours a week with their coaches, their coach can have a huge impact on the fulfillment of their basic needs.

Mageau and Vallerand (2003) specifically looked at how coaches' actions impact the fulfillment of their athletes' basic needs. They identified a series of positive behaviors that they coined as autonomy supportive coaching. Autonomy supportive coaching identifies a number of positive behaviors coaches can adapt to support the basic needs of their athletes. Mageau and Vallerand recognize that autonomy supportive coaching is similar to Baumrind's (1991) authoritative parenting style.

Baumrind (1991) identified four parenting styles based on the parents' level of demandingness and responsiveness. In the case of an authoritative parent, they are highly demanding and highly responsive. While Baumrind's parenting styles have been applied to parents' impact on their children and teachers on their students, very few have applied it to coaches' impact on their athletes. Brinton (2015) was the first to adopt Baumrind's parenting styles to coaching, but the focus was on youth coaches. Therefore, the purpose of this study was 
to determine to what extent a coach's coaching style is associated with the athlete's basic psychological needs fulfillment of autonomy, competence and relatedness.

\subsection{Purpose of the Study}

The purpose of this study was to determine to what extent a coach's coaching style is associated with the athlete's basic psychological needs fulfillment of autonomy, competence and relatedness.

\section{$\underline{1.3 \text { Research Questions }}$}

The following research questions will be answered through this study.

1. Is coaching style associated with a college athletes' perception of basic psychological needs fulfillment (i.e. competence, autonomy, and relatedness)?

2. To what extent is a permissive coaching style associated with the basic psychological needs fulfillment in college athletes?

3. To what extent is an authoritarian coaching style associated with the basic psychological needs fulfillment in college athletes?

4. To what extent is an authoritative coaching style associated with the basic psychological needs fulfillment in college athletes?

\section{$\underline{1.4 \text { Delimitations }}$}

This study will be limited to student athletes at Cal Poly, San Luis Obispo (Cal Poly). Therefore, the sample of students may have some similarities, since they all come from the same college environment. Their coaches may also share some similarities, since they all work for the same athletic director and athletic department. There may still be some variation between athletes and coaches due to different experiences, genders, sports and years in school. 


\subsection{Summary}

Overall, this study sought to continue the conversation of how coaches impact athletes' psychological wellbeing at all levels. This study expands the conversation to college athletes. Through the study of Cal Poly student athletes, college coaches and administrators can begin to understand how their behaviors impact their student athletes and possibly make adjustments that will positively benefit everyone involved. 


\section{CHAPTER 2}

\section{LITERATURE REVIEW}

With the rise of college coaches being accused of verbal and physical abuse, it is important to look at the impact of coaching styles on the basic psychological needs of college athletes. Smith and Smoll (1979) found in a study of youth baseball coaches that a coaches' style has an impact on the athlete's satisfaction with playing the sport. And most importantly they found that a small intervention can lead to changes in the coaches' behavior. As a result, the athletes have greater satisfaction. This literature review will explore the basic psychological needs, how they are fulfilled and the role of coaches in fulfilling these needs.

\subsection{Self-Determination Basic Needs Theory}

The basic needs theory lays out that individuals have three basic needs they need fulfilled in order to live a balanced and psychologically fulfilling life. Individuals need to feel autonomous, competent and have a sense of relatedness to the people around them (Ryan \& Deci, 2000).

2.1.1 Relatedness. Athletes feel a sense of relatedness when they believe their coach cares about them beyond their performance. Relatedness has not been studied in detail because it is hard to capture. However, when it is studied in tandem with competence and autonomy it is identified as an important factor. Those who feel a sense of relatedness have higher rates of internal motivation (Niemiec \& Ryan, 2009).

2.1.2 Competence. Athletes that have high levels of competence believe they have the ability to complete the tasks they are asked to complete. Competence has been found to be a key predictor of an athletes' psychological well-being (Reinboth, Duda, \& Ntoumanis, 2004; Mallett, 
2005; Niemiec \& Ryan, 2009). Reinboth et al. found that athletes whose coaches focused on the process and gave feedback on the process had higher levels of competence. These findings have been supported by other research exploring college athletics (Mageau \& Vallerand, 2003;

Mallett). Others have found that an athlete's competence is tied to the type of tasks that are asked of them. If a task is optimally challenging and a coach provides the tools and feedback to complete the tasks, then the athlete will have greater competence (Niemic \& Ryan).

2.1.3 Autonomy. Athletes who feel they have control of the decisions and have the tools to make the correct decision experience a high level of autonomy (Ryan \& Deci, 2000; Niemiec \& Ryan, 2009). Autonomy is promoted by coaches when they give athletes the ability to make decisions. In a sports context, that might mean that a coach gives the athlete the freedom to decide what play they want to run, or they give them options in the drill and the athlete must make the decision on what option they want to do. It can also be as simple as the athlete picking what they want to eat for a pre-game meal or what socks they wear. A coach can thwart the need for autonomy by controlling practices such as controlling feedback, excessive personal control, intimidation behaviors and promoting ego-involvement (Mallett, 2005; Bartholomew, Ntoumani, \& Thogersen-Ntoumani, 2009).

The basic needs can be fulfilled or thwarted by an individual's environment. When individuals feel these basic psychological needs are fulfilled then they have greater intrinsic motivation and experience higher self-esteem (Niemiec \& Ryan, 2009). In the case of athletes, the benefits also apply to the on-court performance. Athletes whose high basic needs fulfillment experience higher internal motivation (Amorose \& Anderson-Butcher, 2006). As a result, these athletes, have great preservation through adversity and tend to work hard towards their goals (Mallett, 2005; Amorose \& Anderson-Butcher). These outcomes are very beneficial to the athlete 
as well as those who coach the athlete. Therefore, coaches should be interested in how to promote the basic needs of their student athletes.

Basic needs fulfillment has been found to be impacted by individuals' environments. Their environment includes both their physical environment and the interpersonal relationships they have in their physical environment. In the study of coach-athlete relationships, each of these factors has been examined.

\section{2 Gaps in Literature}

Throughout the literature, it is clear that coaches can impact the basic needs fulfillment of their athletes. Current research highlights practices that either promote or thwart basic needs fulfillment, but researchers have struggled to present a clear picture of what coaching styles promote basic needs fulfillment. By exploring coaching styles, coaches are presented a broader framework to follow. For example, there might be a situation that has not been looked at specifically, but if the underlying approach that promotes basic needs fulfillment can be understood, then that approach can be applied to any situation. By exploring coaching styles, coaches will have better information to create an environment and program that promotes the basic needs fulfillment of their athletes.

A current challenge to research around coaching styles is that there is no clear definition of coaching styles. Current models overlap and have limited foundational research. In response, this study is uses Baumrind's parenting styles to define distinct coaching styles. Baumrind's parenting styles have been applied to the classroom in relationship to students, as well as recently

in the coaching literature (Turner, Chandler, \& Heffer, 2009; Brinton, Hill \& Ward, 2017). Research has found that Baumrind's parenting styles translates accurately to the teacher-student relationship (Turner, et al.). The teacher-student relationship is transferable to the coach-athlete 
relationship, therefore the Baumrind's parenting styles is an appropriate model to be used to define coaching styles.

\section{$\underline{2.3 \text { Baumrind's Parenting Model }}$}

In Baumrind's (1991) model, there are four styles: authoritarian, authoritative, permissive, neglectful (p. 61). The four styles are different combinations of demandingness and responsiveness/support. Baumrind defines demandingness as "the claim parents make on children to become integrated into the family whole, by their maturity demands, supervision, disciplinary efforts, and willingness to confront the child who disobeys" (p. 61-62). A parent who has high demandingness expects their child to behave in a way that is clearly defined and enforced by the parents. Responsiveness is "the extent to which parents intentionally foster individuality, self-regulation, and self-assertion by being attuned, supportive, and acquiescent to children's special needs and demands" (Baumrind, p. 62). A parent who is highly responsive is aware of their child's needs and will do what they can to provide for those needs. The four parenting styles exist on a scale of demandingness and responsiveness.

2.3.1 Neglectful. A neglectful parent is low in demandingness and responsiveness. They do not set clear expectations or rules for their children, and they are not aware of their children's needs. A child who is raised by neglectful parents may experience a number of negative outcomes including low self-esteem, low school performance, low competence and is more likely to engage in problematic drug use (Baumrind, 1991; DeHart, Pelham, \& Tennen, 2006; Lamborn, et al., 1991).

2.3.2 Permissive. A permissive parent is very responsive to their children's needs but does not set clear rules or discipline their child. A permissive parent is more interested in being a support system for their child. They do not set clear boundaries or expectations for their children 
which can result in similar behavioral issues outlined above that are experienced by children in neglectful homes (Baumrind, 1991; Lamborn et al., 1991). DeHart et al. (2006) hypothesized that children in permissive homes might have high self-esteem because they are coming from a nurturing home, but they found the opposite. They believed this was the case because children are receiving mixed messages from their parents. The children are nurtured, but the lack of discipline also communicates to the children that the parents might not really care. In addition, Barton and Hirsch (2015) found that children raised in permissive homes struggle in college because they have a sense of academic entitlement which leads to low discipline in the classroom. If tasks do not come easy, these children have not build up the 'psychological capital' to overcome new challenges (Barton \& Hirsch; Jafri, 2017).

In a coaching setting, a permissive coach would be very supportive of the needs of his athletes but not be very demanding. This coach would be described more as a friend versus an authority figure. Without any structure or discipline, the athlete's development in the sport might be stagnant. These athletes would be predicted to have high levels of relatedness and autonomy but low competence.

2.3.3 Authoritarian. Authoritarian parents are very demanding but very low in responsiveness. They set strict and clear rules and follow them with discipline. However, they are not attuned to their child's needs. Another clear characteristic of authoritarian parents is they do not offer rationale or reasons for their rules. It is very much a "because I said so" approach to parenting. Children raised by authoritarian parents are very obedient and perform well in school (Baumrind, 1991; Lamborn et al., 1991), but they have low levels of self-esteem and lack competence and autonomy (Baumrind; Lamborn et al.; DeHart et al., 2006). Authoritarian parents do not give their children enough responsibilities and autonomy to develop the 
competence they need to transition into adulthood (Lamborn et al). DeHart et al. also found that the lack of responsiveness lead to low self-esteem because they were not nurtured enough by their parents. Overall, children who are raised by authoritarian parents do not experience behavioral issues, but struggle to develop the self-esteem and gain the autonomy and competence to transfer into adulthood well.

An authoritarian coach is demanding but not very responsive to the needs of the athlete or supportive of the athlete. The strict rules and expectations provide the structure to help the athlete advance in the sport, but the athlete might lack the feeling of support. As a result, athletes in this setting would be predicted to have high levels of competence, but low autonomy and relatedness.

2.3.4 Authoritative. Authoritative parents are very demanding and highly responsive. They set clear expectations for their children and give rationale for why those are the expectations. They are attuned to the needs of their children and work to balance discipline and support. Children raised by authoritative parents have high self-esteem, high levels of competence, perform well in school and are less likely to abuse drugs (Baumrind, 1991; Lamborn et al., 1991; DeHart et al., 2006). McCormick, Turner, and Foster (2015) also found that children raised by authoritative parents experienced greater feelings of self-worth in college and lead to better overall mental health.

An authoritative coach is demanding but also very responsive and supportive. Authoritative coaches put high demands on their athletes but also provide them the support to accomplish their demands. An athlete with an authoritative coach would be predicted to have all three basic needs supported; autonomy, competence and relatedness (Mageau \& Vallerand, 2003). 
While very little research has applied Baurmind's parenting styles directly to coaching, there is another arm of literature that closely resembles Baumrind's authoritative parenting style called autonomy supportive coaching. In the classroom setting, Niemiec and Ryan (2009) defined an autonomy-supportive environment as an environment that minimizes evaluative pressure and emphasizes the "why" when teaching concepts. An environment that promotes competence has optimally challenging activities and provides tools and feedback. And finally, in an environment that promotes relatedness the students feel like the teacher genuinely likes, respects and values them, aligning with Baumrind's description of an authoritative parent.

In the athletics setting, the autonomy supportive coaching environment has been found to result in greater satisfaction of an athlete's basic needs outlined above as well as greater intrinsic motivation (Mageau \& Vallerand, 2003; Amorose \& Anderson-Butcher, 2006; Adie, Duda, \& Ntoumanis, 2008). Due to higher levels of intrinsic motivation and a supportive environment, Autonomy supportive coaching environments are also associated with lower levels of burn-out among elite athletes (Balaguer et al., 2012; Isoard-Gautheur, Guillet-Descas, \& Lemyre, 2013).

Autonomy supportive coaching is similar to Baumrind's parenting styles, but it has distinct differences. The biggest difference between the two is an autonomy supportive coach is defined by a set of practices that have been deemed "good." Conversely, Baumrind's parenting styles exist on a scale of demandingness and responsiveness. There are not certain practices defined as good and bad. The concept is more fluid and, therefore, it can be applied to many situations.

\subsection{Area of Exploration}

This study explored how each coaching style either thwarts or fulfills the basic needs of athletes. The coaching style of a coach impacts the athletes' environment and therefore can play 
a role in their basic needs fulfillment. For example, a coach that is highly demanding is going to impact the autonomy and competence of an athlete. The exact impact will depend on the level of responsiveness of that coach. If a coach is highly responsive and highly demanding, then the athlete could experience high levels of competence because they believe they can accomplish challenging tasks. A highly responsive coach is likely to have a good relationship with the athlete and, therefore, would promote relatedness and possibly autonomy. By looking at the relationship between coaching style and the athletes' basic need fulfilment, coaches can begin to understand how they should approach their job in order to bring the best out of the athlete. 


\section{CHAPTER 3}

\section{METHODOLOGY}

\subsection{Study Locale}

The study was conducted at California Polytechnic University San Luis Obispo with male and female athletes from all 20 varsity sports teams.

\subsection{Description of Subjects}

The study looked at college athletes competing in Division I sports at California Polytechnic State University in San Luis Obispo, CA (Cal Poly). These athletes are considered elite in their respective sports since less than $7 \%$ of high school athletes have the opportunity to compete at a Division 1 level in their sport (NCAA, 2017). There are 537 athletes competing at Cal Poly, 238 females (44.3\%) and 299 males (55.7\%), representing 20 sports. Athletes in their first academic term at Cal Poly were excluded. Subjects were asked anonymously to evaluate their head coach and self-select one of their assistant coaches to evaluate.

\subsection{Description of Instruments}

\subsubsection{Basic Needs Fulfillment}

The Basic Needs Satisfaction in Sport Scale (BNSSS). The BNSSS is a five factor Likert scale ranging from 1 to 7 with 7 being high in the construct it measures (Appendix A). The BNSSS measures the participants' perceived levels of autonomy, competence and relatedness (Ng, Lonsdale, \& Hodge, 2010).

\subsubsection{Baumrind's Coaching Style}

Adapted Parental Authority Questionnaire (Adapted PAQ). Brinton (2017) adopted the Adapted PAQ from the Parental Authority Questionnaire (Buri, 1991). Brinton adapted the PAQ 
by rephrasing the statements to reflect a coach-athlete relationship rather than a parent-child relationship (Appendix B). The Adapted PAQ is a 30-item Likert scale ranging from 1 to 5 with 5 being high in the construct it measures. It gives a score for an authoritative, an authoritarian, and a permissive coaching style. The neglectful style is not measured which is in line with previous research. The Adapted PAQ provides a holistic score for the three coaching styles for each coach.

\section{$\underline{3.4 \text { Study Procedures }}$}

The participants are current Cal Poly athletes who have completed at least one term at Cal Poly. The participants were given paper surveys to complete during the winter quarter (January-March). Participants were asked to evaluate their head coach and one assistant coach

they selected anonymously. Student athletes completed the survey, which included questions to determine the coaching style of their head coach and the assistant coach they selected and their own autonomy, competence and relatedness in their sport. The athletes were all in different places in their season, some just finished their season, others were in season and some were about to begin their season. The surveys were coded to account for the gender of the athlete and the type of sport they compete in (team or individual).

\subsection{Data Analysis}

Once the data was collected, linear mixed method analysis was used to associate coaching style with the three basic needs. The analysis examined whether a correlation exists between coaching style and the basic need of autonomy, competence or relatedness, while accounting for the type of sport (team or individual) and the gender match between the athlete and the coach (if the gender of the athlete and the coach are the same or different). 


\section{CHAPTER 4}

\section{RESULTS}

This chapter outlines the survey results in order to examine the proposed relationship between coaching style and the athlete's basic needs. The purpose of this study was to determine to what extent a coach's coaching style is associated with the athlete's basic psychological needs fulfillment of autonomy, competence and relatedness. This chapter presents the results of the survey.

\subsection{Respondent Demographics}

The target population was the 537 student-athletes enrolled in at least their second term at Cal Poly representing 20 sports. From that target population, 13 of the 20 sports agreed to participate in the study. Therefore, 220 student-athletes were asked to participate in the study ( $41 \%$ coverage rate). Of the 220 student-athletes, there were 204 survey respondents $(92.7 \%$ response rate). The 204 survey respondents represented 110 male student-athletes (94\% response rate) and 94 female student-athletes (91.3\% response rate). There were eight team sports and five individual sports surveyed. At the time of the survey, three teams had just finished their season, four teams were in season, and six teams were about to start their season. Of the teams surveyed, four female teams had a female head coach, three female teams had a male head coach and all six male teams had a male head coach.

Based on the mean scores for each coaching style, the athletes on average ranked their coaches as more authoritative than authoritarian or permissive. In fact, permissive was a lot lower than authoritative or authoritarian. The pooled standard deviation gives a sense of how much each athlete's response varies from the mean within their own team (Table 1). 
Table 1

Mean and Standard Deviation of Coaching Styles of Head Coaches

\begin{tabular}{lccc}
\hline Coaching Style & $\mathrm{n}$ & $\mathrm{M}^{\wedge}$ & Pooled SD \\
\hline Permissive & 194 & 2.49 & 0.52 \\
Authoritarian & 194 & 3.31 & 0.55 \\
Authoritative & 194 & 3.61 & 0.63 \\
\hline
\end{tabular}

${ }^{\wedge}$ Likert scale 1-5

The same evaluation for assistant coaches yielded a similar result. Athletes on average rated their assistant coaches highest in authoritative style and least in permissive style. However, in the case of the pooled standard deviation there is more variation from the mean within each team than what was seen among head coaches (Table 2).

Table 2

Mean and Standard Deviation of Coaching Styles of Assistant Coaches

\begin{tabular}{lccc}
\hline Coaching Style & $\mathrm{n}$ & $\mathrm{M}^{\wedge}$ & Pooled SD \\
\hline Permissive & 182 & 2.53 & 0.61 \\
Authoritarian & 182 & 3.00 & 0.66 \\
Authoritative & 182 & 3.53 & 0.72 \\
\hline
\end{tabular}

${ }^{\wedge}$ Likert scale 1-5

A multivariate ANOVA test was run to determine if there is a significant difference between the means of each team for all three coaching styles. A significant difference was found for both head coaches and assistant coaches (Table 3). Therefore, it can be said that the teams rate their head coaches differently on average, as well as their assistant coaches. The box plot below gives a visual of the variation in each head coach's score in the authoritative coaching 
style category (Figure 1). In order to maintain anonymity, we did not label each team included in the plot.

Table 3

Multivariate ANOVA for Head Coaches and Assistant Coaches

\begin{tabular}{lccc}
\hline Source & Df & F & $p$ \\
\hline Head Coaches & 12 & 5.08 & $0.00 * *$ \\
Assistant Coaches & 11 & 7.81 & $0.00 * *$ \\
$* * p<.01$ & & &
\end{tabular}

Figure 1

Box Plot of Each Head Coach's Authoritative Coaching Style Score

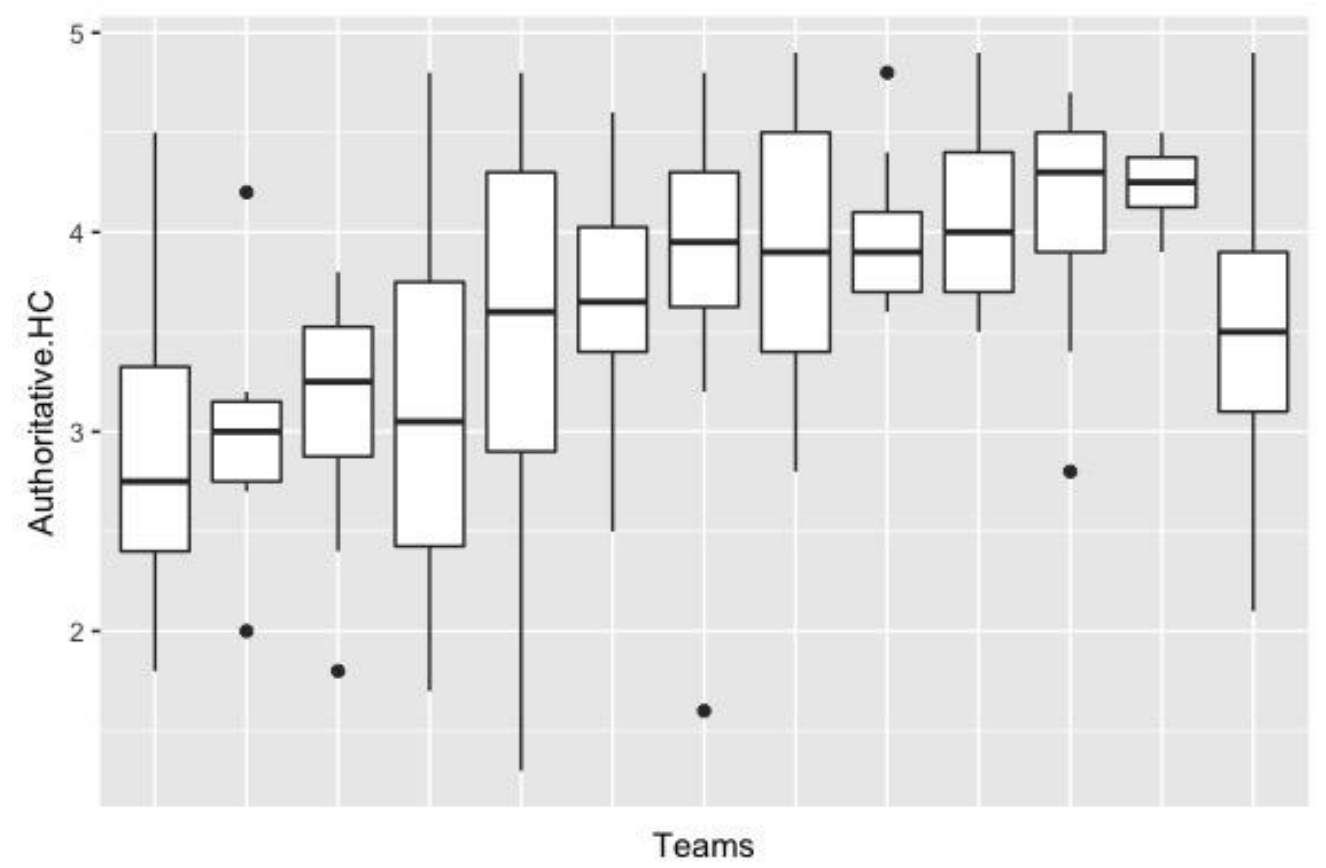

The mean scores for the athlete's basic needs show on average athletes ranked their relatedness as the highest, followed by competence and autonomy. In each case, the mean would be categorized as on the higher end of a seven-point Likert scale with seven being the highest. 
Each of these measures also show a similar standard deviation, indicating an even spread of values across all three basic needs (Table 4).

Table 4

Mean and Standard Deviation of Athletes' Basic Needs

\begin{tabular}{lccc}
\hline Basic Needs & $\mathrm{n}$ & $\mathrm{M}^{\wedge}$ & $\mathrm{SD}$ \\
\hline Autonomy & 206 & 5.226 & 0.81 \\
Competence & 206 & 6.049 & 0.82 \\
Relatedness & 206 & 6.197 & 0.83 \\
\hline
\end{tabular}

${ }^{\wedge}$ Scale 1-7

The multivariate ANOVA of the athlete's basic need shows there is also a significant difference between the means of each team for the athletes' basic needs fulfillment (Table 5).

Table 5

Multivariate ANOVA for Athletes' Basic Needs

\begin{tabular}{lccc}
\hline Source & Df & F & $p$ \\
\hline All Basic Needs & 12 & 2.42 & $0.00^{* *}$ \\
\hline$* * p<.01$ & & &
\end{tabular}

The study also looked at how the athlete's basic need satisfaction varied by the gender of the athlete. There was no difference in an athlete's autonomy or competence based on gender, but female athletes reported a significantly higher relatedness score than male athletes (Table 6). 
Table 6

Basic Needs Satisfaction by Gender of Athlete

\begin{tabular}{|c|c|c|c|c|c|c|}
\hline \multirow[b]{2}{*}{ Basic Needs } & \multicolumn{2}{|c|}{$\begin{array}{c}\text { Male } \\
(n=110)\end{array}$} & \multicolumn{2}{|c|}{$\begin{array}{l}\text { Female } \\
(n=94)\end{array}$} & \multirow[t]{2}{*}{$t$} & \multirow[t]{2}{*}{$p$} \\
\hline & $M$ & $S D$ & $M$ & $S D$ & & \\
\hline Autonomy & 5.17 & 0.83 & 5.16 & 0.82 & 0.52 & 0.61 \\
\hline Competence & 5.99 & 0.88 & 6.05 & 0.79 & -0.20 & 0.84 \\
\hline Relatedness & 6.07 & 0.90 & 6.32 & 0.73 & -2.26 & $0.03 * *$ \\
\hline
\end{tabular}

A similar result was found when the athlete's basic need satisfaction was compared for athletes in individual sports versus team sports. There was no difference in an athlete's autonomy or competence based on type of sport, but team sport athletes reported a significantly higher relatedness score than individual sport athletes as displayed in Table 7.

Table 7

Basic Needs Satisfaction by Team Type

\begin{tabular}{|c|c|c|c|c|c|c|}
\hline \multirow[b]{2}{*}{ Basic Needs } & \multicolumn{2}{|c|}{$\begin{array}{c}\text { Individual } \\
\text { sport } \\
(n=5) \\
\end{array}$} & \multicolumn{2}{|c|}{$\begin{array}{c}\text { Team sport } \\
(n=8)\end{array}$} & \multirow[t]{2}{*}{$t$} & \multirow[t]{2}{*}{$p$} \\
\hline & $M$ & $S D$ & $M$ & $\mathrm{SD}$ & & \\
\hline Autonomy & 4.94 & 0.86 & 5.23 & 0.80 & -1.34 & 0.18 \\
\hline Competence & 6.02 & 0.88 & 6.02 & 0.79 & 0.44 & 0.66 \\
\hline Relatedness & 5.88 & 0.90 & 6.30 & 0.73 & -3.33 & $0.00 * *$ \\
\hline
\end{tabular}




\subsection{Linear Mixed Model Regression}

A linear mixed model regression was used to determine the relationship between coaching style and the three basic needs of athletes. The following equation was used:

$$
\begin{aligned}
& \mathrm{y}_{\mathrm{ijk}}=\alpha+\mu_{\mathrm{j}}+\mu_{\mathrm{k}}+\delta_{\mathrm{j}} \mathrm{x}_{\mathrm{ijk}}+\beta \mathrm{x}_{\mathrm{ijk}}+\varepsilon_{\mathrm{ijk}} \\
& \mathrm{y}_{\mathrm{ijk}}=\text { target measure (relatedness, competence, overall autonomy) for athlete } \mathrm{i} \text {, gender } \\
& \text { match } \mathrm{j} \text { and team } \mathrm{k} \\
& \alpha=\text { overall mean } \\
& \mu_{\mathrm{j}}=\text { team mean } \\
& \mu_{\mathrm{k}}=\text { gender match mean } \\
& \delta_{\mathrm{j}}=\text { gender match effect } \\
& \beta=\beta_{1}, \beta_{2}, \beta_{3}=\text { fixed effect for a permissive (1), authoritarian (2), or authoritative (3) } \\
& \text { coach } \\
& \mathrm{x}_{\mathrm{ijk}}=\left(\mathrm{x}_{1 \mathrm{ijk}}, \mathrm{x}_{2 \mathrm{ijk}}, \mathrm{x}_{3 \mathrm{ijk}}\right)=\text { coach measures (permissive, authoritarian, authoritative) } \\
& \varepsilon_{\mathrm{ijk}}=\text { random error }
\end{aligned}
$$

The equation accounts for random effects including the team as well as the gender match component. The gender match component controls for the potential effect of having a female athlete and a female coach versus a female athlete and a male coach or vice versa. This is important to account for since the gender of the coach and the athlete could affect their relationship. The equation also controlled for the team, so that a response from an athlete on a small team would be weighed equally to a response from an athlete on a large team. In order to make sure, the big teams did not skew the results. However, due to the sensitive nature of the data the team level data and results will not be reported. A more simplified model is shown in Figure 1. 
Initially, the model included all three coaching styles (permissive, authoritarian and authoritative) and then dropped one at a time top down. The lowest $\beta$ coefficient was dropped, then the model was rerun and then an ANOVA was run to determine if the model was affected by dropping that coaching style. If the ANOVA was not significant, the process continued. The same method was followed until the ANOVA was significant. Then the previous model was used since dropping that coefficient significantly impacted the model. A top down progression was used for each target measure for head coaches and then for assistant coaches. Table 6 includes the $\beta$ estimates of head coaches and Table 7 the $\beta$ estimates of assistant coaches. Only 11 teams had assistant coaches, so the $\beta$ estimates for Table 6 only include 11 teams, excluding men's and women's golf. 

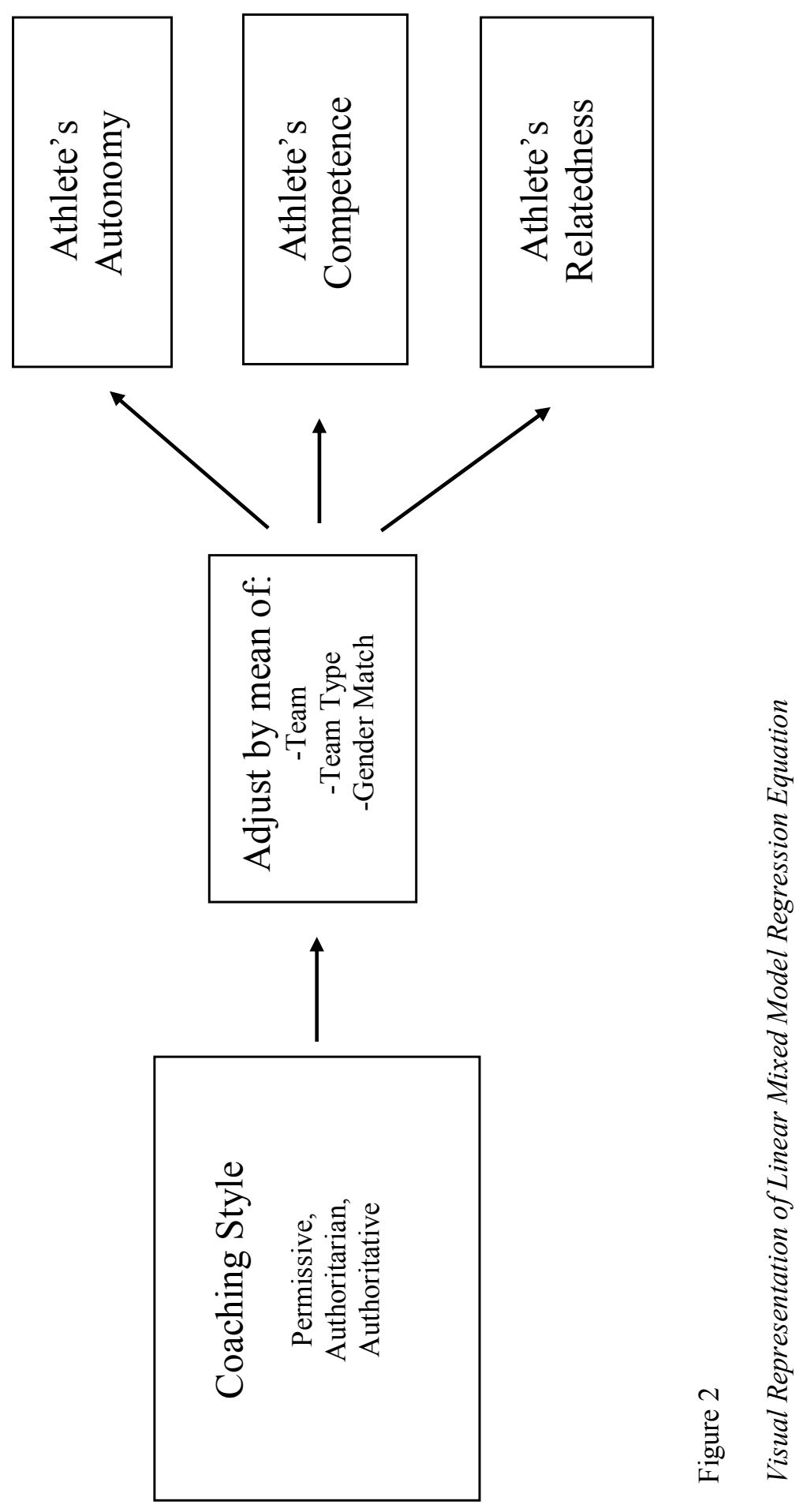
Table 8

Summary of Linear Regression for Head Coach's Coaching Style Predicting Basic Needs

\begin{tabular}{lcccccc}
\hline & \multicolumn{2}{c}{ Permissive } & \multicolumn{2}{c}{ Authoritarian } & \multicolumn{2}{c}{ Authoritative } \\
\cline { 2 - 6 } Basic Needs & $B$ & $S E B$ & $B$ & $S E B$ & $B$ & $S E B$ \\
\hline Autonomy & 0.11 & 0.10 & -0.22 & 0.10 & $0.65^{* *}$ & 0.10 \\
Competence & 0.12 & -0.01 & 0.12 & 0.03 & $0.56^{* *}$ & 0.11 \\
Relatedness & 0.01 & 0.52 & -0.10 & 0.10 & $0.44^{* *}$ & 0.13 \\
\hline$* * p<.01$ & & & & & &
\end{tabular}

Table 9

Summary of Linear Regression for Assistant Coach's Coaching Style Predicting Basic Needs

\begin{tabular}{lcccccc}
\hline & \multicolumn{2}{c}{ Permissive } & \multicolumn{2}{c}{ Authoritarian } & \multicolumn{2}{c}{ Authoritative } \\
\cline { 2 - 6 } Basic Needs & $B$ & $S E B$ & $B$ & $S E B$ & $B$ & $S E B$ \\
\hline Autonomy & -0.05 & 0.29 & -0.09 & 0.08 & $0.22^{*}$ & 0.10 \\
Competence & -0.05 & 0.12 & -0.09 & 0.08 & $0.30^{* *}$ & 0.08 \\
Relatedness & -0.11 & 0.14 & 0.07 & 0.08 & $0.21^{* *}$ & 0.06 \\
\hline$* p<.05, * * p<.01$ & & & & & &
\end{tabular}

For both head coaches and assistant coaches, an authoritative coaching style was significantly associated with higher levels of perceived autonomy, competence and relatedness in their athletes. In the case of head coaches, an increase in authoritative coaching style is associated with a 0.65 increase in their athlete's perceived autonomy, as well as a 0.56 increase in competence and 0.44 increase in relatedness (Table 8). Overall, an authoritative coaching style has a positive impact on athlete's perception of the fulfillment of all three basic needs. 
Assistant coaches with an authoritative coaching style also had a positive impact on athlete's three basic needs as displayed in Table 9. For both head coaches and assistant coaches, permissive and authoritarian coaching styles did not have a statistically significant impact on autonomy, competence or relatedness.

\subsection{Summary}

This chapter has presented the results from the survey. Through a linear mixed model regression, the effect of coaching style was determined on the autonomy, competence and relatedness of athletes. The concluding chapter will discuss these findings, the implications for coaches and athletic administration, and identify study limitations and opportunities for future research 


\section{CHAPTER 5}

\section{DISCUSSION}

The purpose of this study was to determine to what extent a coach's coaching style is associated with the athlete's basic psychological needs fulfillment of autonomy, competence and relatedness. By looking at the athlete's perception of their coaches as well as their own basic needs fulfillment, a relationship was determined. This chapter will review the methodology, summarize the results and discuss the findings in relationship to prior research. Further research and practical implications will also be discussed.

\subsection{Summary}

The results of this study provide insight into the impact of college coaches' coaching style on the basic needs fulfillment of college athletes. Each athlete completed an Adapted Parental Authority Questionnaire (APAQ) to evaluate the styles of their head coach and an assistant coach of their choice. The results of the APAQ gave each coach a score of authoritarian, authoritative, and permissive style. At the same time, each athlete evaluated their own level of autonomy, competence and relatedness in their sport using the Basic Needs Satisfaction in Sports Scale (BNSSS). In order to determine the impact of the coach's style on the well-being of the athlete, a mixed linear regression evaluated if a coach's score in one of the three areas is associated with the autonomy, competence or relatedness of the athlete in their sport.

Through this analysis, there was a significant positive relationship between an authoritative head coach and an athlete's reported autonomy $(\beta=0.65)$, competence $(\beta=0.56)$ and relatedness $(\beta=0.44)$ in their sport. For assistant coaches, the effect was smaller but still significant, autonomy $(\beta=0.22)$, competence $(\beta=0.30)$, and relatedness $(\beta=0.21)$. The 
authoritarian and permissive styles of a coach did not have a significant relationship on the autonomy, competence and relatedness of the athlete. These findings show that coaching styles can positively impact the basic needs of college athletes.

\subsection{Discussion and Practical Implication}

The overall findings from the study were that an authoritative coaching style for both head coaches and assistant coaches has a positive impact on the fulfilment of an athlete's basic needs, autonomy, competence and relatedness. However, the impact was found to be greater for head coaches than assistant coaches. Based on what is known about the impact of environment on the fulfillment of basic needs, this finding is not surprising. As discussed previously, it is understood that the environment of an individual can impact their basic needs fulfillment (Ryan \& Deci, 2000; Mageau \& Vallerand, 2003; Niemiec \& Ryan, 2009). In the case of coaches, a head coach has a greater impact on their athlete's environment than assistant coaches since head coaches typically run practices, determine playing time and set the culture of the team. Since a head coach has a greater impact on the environment it makes sense that their coaching style has a greater impact on the athlete's basic needs fulfillment than an assistant coach's coaching style.

By evaluating the descriptive statistics, it is evident that there is a difference between male and female athletes levels of relatedness (Table 4). Therefore, it is important to control for gender since it has an impact on the athlete's relatedness. Also, team type was found to also have an impact on relatedness. Athletes in team sports experienced higher relatedness on average than athletes in individual sports (Table 5). Since team sports require more interaction and cooperation between teammates, it would make sense athletes in team sports would experience more relatedness in their sport. The difference also supports the notion to account for what team 
type the athlete is competing in when trying to understand how their sport fulfills their basic needs.

Overall, the relationship between authoritative coaching style and the autonomy, competence and relatedness of college athletes is in line with previous research on the impact of coaches on athletes. Brinton et al. (2017) also used Baumrind's parenting styles to evaluate coaching styles. Through his research of club and high school level coaches as recalled by college freshman, he also found that an authoritative coaching style had a significant impact on autonomy, competence and relatedness of their athletes. Mageau and Vallerand's (2003) motivational model also supports these findings. They describe the authoritative coaching style as autonomy-supportive behaviors.

This research contributes to and strengthens Brinton (2017) and Mageau and Vallerand's (2003) findings. Unlike Brinton, this research evaluates the athletes and their coaches at a moment in time. Brinton's retrospective study asked college freshman to recall their coach from a high school or club team allowing for potential recall bias. Recall bias could potentially lead to more favorable or worse evaluation of coaches based on how the student remembers their experience playing club or high school sports. However, when the athletes were evaluated in a moment in time the same results were found supporting Brinton's findings. In addition, this study evaluates college athletes and coaches showing that these findings support elite athletes as well as high school athletes.

Finally, these findings further contribute to Mageau and Vallerand's (2003) motivational model. Rather than contributing certain practices, this study gives a broader interpretation of effective practices. Baumrind defines authoritative practices as very demanding and highly responsive. While many of Mageau and Vallerand's practices strike a balance between 
demandingness and responsiveness they might not be able to cover every situation a coach might find themselves in. This study helps broaden their model and allows coaches to apply a more general philosophy to their situation, the balance of demandingness and responsiveness.

In addition, this study can help athletic administrators, especially athletic directors, understand the impact of current coaches and potential hires on the psychological well-being of athletes. With the understanding that authoritative coaching styles have a positive impact, they can evaluate if their coach's actions create a highly supportive and highly demanding environment for their athletes.

Coaches that engage in authoritative behaviors have a positive impact on the autonomy of their athletes which has been found to result in higher intrinsic motivation (Mageau \& Vallerand, 2003; Amorose \& Anderson-Butcher, 2006; Adie, Duda, \& Ntoumanis, 2008). According to the $\beta$ estimates, an authoritative head coach has the largest effect on the basic need of autonomy (0.65). As discussed before, intrinsic motivation leads to lower burnout which is a common problem among elite athletes (Balaguer et al., 2012; Isoard-Gautheur, Guillet-Descas, \& Lemyre, 2013). Greater athlete retention is very important to athletic departments because every athlete they retain is worth one of two APR points. Athletic departments have to achieve a certain APR to receive a large sum of NCAA funding hence, retaining athletes is key. In addition, athlete retention creates a stable environment and can be beneficial to the health of the program and recruiting. Therefore, athletic administrators might be very interested in learning that authoritative coaching style can contribute to the autonomy of their athletes and as a result, increase intrinsic motivation and ultimately lead to retention. And in this era of the NCAA, athlete retention equates to NCAA funding. 


\subsection{Limitations}

This study had some limitations. First, the athletes were all surveyed during the same academic term. Therefore, each of the athletes were at a different point in their season. Some just finished, some were in the middle of their season and others were about to begin. As a result, the athlete's playing time, the outcome of the season or the hope they had for their season could impact both the athlete's perception of their basic needs fulfillment as well as their views of their coach either positively or negatively. We attempted to negate this impact by evaluating the entire team and all the teams at the same time. There was also a variation in where teams were in their season.

In addition, not every team participated in the study. Since some teams declined to participate it is possible they might have different cultures than the teams that participated. As a result, we might have missed out on a certain subset of the coaches. However, as we saw in the Multivariate ANOVA for head coaches and assistant coaches (Table 3) here is still significant variation between the coaches whose teams did participate.

Another limitation of this study was the need to keep it anonymous. Since the data collected was sensitive data could not be collected on potential factors that could impact the athlete's basic needs and their view of their coach's behavior. For example, it could have been beneficial to know the athlete's year in school, role on the team or how close they live to their home town.

Finally, this study was limited to one athletic department. Even though the coaches were hired by different athletic directors and administrations, inherently there will be some continuity between how the coaches approach their job. Therefore, there might not be enough variability in the coaching styles to find effects across all three coaching styles. If very few of the coaches 
engage in permissive behaviors, then we might not gain a true understanding of the potential effects of a permissive coach on the athlete's basic needs fulfillment.

\subsection{Future Research}

Most of the research on the impact of coaches on athletes is focused on the perception of athletes on their coach's behaviors. While ultimately, the athlete's perception is what is important, future research should explore the coach's own perception of their behavior. It is important to understand how coaches understand their own behaviors. It could be that they think they are engaging in authoritative behaviors, as is recommended, but their athletes perceive their actions as authoritarian. In this case, the coach would not be aware and therefore, could not make the changes they need to for the athletes to perceive their behaviors as they wish they would. Ultimately, this research is only helpful if the coaches know how their actions are being perceived by their athletes and how to adjust. 


\section{REFERENCES}

Adie, J. W., Duda, J. L., \& Ntoumanis, N. (2008). Autonomy support, basic need satisfaction and the optimal functioning of adult male and female sport participants: A test of basic needs theory. Motivation and Emotion, 32(3), 189-199. doi:10.1007/s11031-008-9095-z

Amorose, A. J., \& Anderson-Butcher, D. (2007). Autonomy-supportive coaching and selfdetermined motivation in high school and college athletes: A test of self-determination theory. Psychology of Sport and Exercise, 8(5), 654-670.

doi:10.1016/j.psychsport.2006.11.003

Balaguer, I., Gonzalez, L., Fabra, P., Castillo, I., Merce, J., \& Duda, J. L. (2012). Coaches’ interpersonal style, basic psychological needs and the well- and ill-being of young soccer players: A longitudinal analysis. Journal of Sports Sciences, 30(15), 1619-1629. doi:10.1080/02640414.2012.731517

Bartholomew, K. J., Ntoumanis, N., \& Thogersen-Ntoumani, C. (2009). A review of controlling motivational strategies from a self-determination theory perspective: Implications for sports coaches. International Review of Sport and Exercise Psychology, 2(2), 215-233. Retrieved from http://www.bham.ac.uk

Barton, A. L., \& Hirsch, J. K. (2016). Permissive parenting and mental health in college students: Mediating effects of academic entitlement. Journal of American College Health, 64(1), 1-8. doi:10.1080/07448481.2015.1060597

Baumrind, D. (1991). The influence of parenting style on adolescent competence and substance use. The Journal of Early Adolescence, 11(1), 56-95. doi:10.1177/0272431691111004 
Brinton, C. S., Hill, B. J., \& Ward, P. J. (2017). Authoritative coach: Building youth through sport. Journal of Park \& Recreation Administration, 35(1). doi:10.18666/JPRA-2017V35-I1-7296

Buri, J. R. (1991). Parental authority questionnaire. Journal of Personality Assessment, 57(1), 110-119. Retrieved from http://www.personality.org

DeHart, T., Pelham, B. W., \& Tennen, H. (2006). What lies beneath: Parenting style and implicit self-esteem. Journal of Experimental Social Psychology, 42(1), 1-17. doi:10.1016/j.jesp.2004.12.005

Isoard-Gautheur, S., Guillet-Descas, E., \& Lemyre, P. (2013). Prospective study of the influence of perceived coaching style on burnout propensity in high level athletes: Using a selfdetermination theory perspective. Sport Psychologist, 26, 282-298. Retrieved from http://www.journals.humankinetics.com

Jafri, M. H. (2017). Understanding perceived parenting styles on student's psychological capital. International Education and Research Journal, 3(5). Retrieved from http://ierj.in

Lamborn, S. D., Mounts, N. S., Steinberg, L., \& Dornbusch, S. M. (1991). Patterns of competence and adjustment among adolescents from authoritative, authoritarian, indulgent, and neglectful families. Child Development, 62(5), 1049-1065. doi:10.1111/j.1467-8624.1991.tb01588.x

Mageau, G. A., \& Vallerand, R. J. (2003). The coach-athlete relationship: A motivational model. Journal of Sports Science, 21(11), 883-904. doi:10.1080/0264041031000140374

Mallett, C. J. (2005). Self-determination theory: A case study of evidence-based coaching. The Sport Psychologist, 19(4), 417-429. Retrieved from http://www.journals.humankinetics.com 
McCormick, W. H., Turner, L. A., \& Foster, J. D. (2015). A model of perceived parenting, authenticity, contingent self-worth and internalized aggression among college students. Personality and Individual Differences, 86, 504-508. doi:10.1016/j.paid.2015.06.050

NCAA (2017). Estimated probability of competing in college athletics. Retrieved from http://www.ncaa.org/about/resources/research/estimated-probability-competing-collegeathletics

Ng, J. Y., Lonsdale, C., \& Hodge, K. (2011). The Basic Needs Satisfaction in Sport Scale (BNSSS): Instrument development and initial validity evidence. Psychology of Sport and Exercise, 12(3), 257-264. doi:10.1016/j.psychsport.2010.10.006

Niemiec, C. P., \& Ryan, R. M. (2009). Autonomy, competence, and relatedness in the classroom: Applying self-determination theory to educational practice. School Field, 7(2), 133-144. doi:10.1177/1477878509104318

Reinboth, M., Duda, J. L., \& Ntoumanis, N. (2004). Dimensions of coaching behavior, need satisfaction, and the psychological and physical welfare of young athletes. Motivation and Emotion, 28(3), 297-313. Retrieved from http://www.bham.ac.uk

Ryan, R. M., \& Deci, E. L. (2000). Self-determination theory and the facilitation of intrinsic motivation, social development, and well-being. American Psychologist, 55(1), 68. Retrieved from http://www.apa.org/pubs/journals/amp/

Smith, R. E., Smoll, F. L., \& Curtis, B. (1979). Coach effectiveness training: A cognitivebehavioral approach to enhancing relationship skills in youth sport coaches. Journal of Sport Psychology, 1(1), 59-75. Retrieved from http://www.journals.humankinetics.com 
Turner, E. A., Chandler, M., \& Heffer, R. W. (2009). The influence of parenting styles, achievement motivation, and self-efficacy on academic performance in college students. Journal of College Student Development, 50(3), 337-346. doi:10.1353/csd.0.0073 


\section{APPENDICES}

Appendix A: Basic Needs Satisfaction in Sport Scale Survey 
Instructions: Please answer the questions according to your feelings and experiences when participating in your main sport.

$1=$ Not True at All

$4=$ Somewhat True

$7=$ Very True

\begin{tabular}{|c|c|c|c|c|c|c|c|}
\hline 1. In my sport, I feel close to other people. & 1 & 2 & 3 & 4 & 5 & 6 & 7 \\
\hline $\begin{array}{l}\text { 2. In my sport, I feel I am pursuing goals that are my } \\
\text { own. }\end{array}$ & 1 & 2 & 3 & 4 & 5 & 6 & 7 \\
\hline 3. I feel I participate in my sport willingly. & 1 & 2 & 3 & 4 & 5 & 6 & 7 \\
\hline 4. In my sport, I get opportunities to make choices. & 1 & 2 & 3 & 4 & 5 & 6 & 7 \\
\hline $\begin{array}{l}\text { 5. In my sport, I feel that I am being forced to do } \\
\text { things that I don't want to do. }\end{array}$ & 1 & 2 & 3 & 4 & 5 & 6 & 7 \\
\hline 6. I can overcome challenges in my sport. & 1 & 2 & 3 & 4 & 5 & 6 & 7 \\
\hline 7. I show concern for others in my sport. & 1 & 2 & 3 & 4 & 5 & 6 & 7 \\
\hline $\begin{array}{l}\text { 8. I choose to participate in my sport according to my } \\
\text { own free will. }\end{array}$ & 1 & 2 & 3 & 4 & 5 & 6 & 7 \\
\hline 9. In my sport, I have a say in how things are done. & 1 & 2 & 3 & 4 & 5 & 6 & 7 \\
\hline 10. There are people in my sport who care about me. & 1 & 2 & 3 & 4 & 5 & 6 & 7 \\
\hline 11. I am skilled at my sport. & 1 & 2 & 3 & 4 & 5 & 6 & 7 \\
\hline
\end{tabular}




\begin{tabular}{|c|c|c|c|c|c|c|c|}
\hline 12. I feel I am good at my sport. & 1 & 2 & 3 & 4 & 5 & 6 & 7 \\
\hline $\begin{array}{l}\text { 13. In my sport, I can take part in decision making } \\
\text { process. }\end{array}$ & 1 & 2 & 3 & 4 & 5 & 6 & 7 \\
\hline $\begin{array}{l}\text { 14. I get opportunities to feel that I am good at my } \\
\text { sport. }\end{array}$ & 1 & 2 & 3 & 4 & 5 & 6 & 7 \\
\hline $\begin{array}{l}\text { 15. In my sport, I really have a sense of wanting to be } \\
\text { there. }\end{array}$ & 1 & 2 & 3 & 4 & 5 & 6 & 7 \\
\hline $\begin{array}{l}\text { 16. In my sport, I feel I am doing what I want to be } \\
\text { doing. }\end{array}$ & 1 & 2 & 3 & 4 & 5 & 6 & 7 \\
\hline 17. I have the ability to perform well in my sport. & 1 & 2 & 3 & 4 & 5 & 6 & 7 \\
\hline 18. In my sport, there are people who I can trust. & 1 & 2 & 3 & 4 & 5 & 6 & 7 \\
\hline 19. I have close relationships with people in my sport. & 1 & 2 & 3 & 4 & 5 & 6 & 7 \\
\hline 20. In my sport, I get opportunities to make decisions. & 1 & 2 & 3 & 4 & 5 & 6 & 7 \\
\hline
\end{tabular}


Appendix B: Adapted Parental Authority Questionnaire 
Instructions: For each of the following statements, circle the number of the 5-point scale (1=strongly disagree, $5=$ strongly agree) that best describes how that statement applies to you and your head coach. Try to read and think about each statement as it applies to you and your coach during your years on the team. There are no right or wrong answers, so don't spend a lot of time on any one item. We are looking for your overall impression regarding each statement. Be sure not to omit any items.

$$
\begin{aligned}
& 1=\text { Strongly Disagree } \\
& 2=\text { Disagree } \\
& 3=\text { Neither Agree or Disagree } \\
& 4=\text { Agree } \\
& 5=\text { Strongly Agree }
\end{aligned}
$$

Gender of your Head Coach: $\quad$ Male $\quad$ Female

1. As a part of the team, my coach feels that on a well-run team the athletes should have their way on the team as often as the coach does.

$\begin{array}{lllll}1 & 2 & 3 & 4 & 5\end{array}$

2. Even if his or her athletes don't agree with him or her, my coach feels that it is for our own good if we are forced to conform to what he or she thinks is right.

$\begin{array}{lllll}1 & 2 & 3 & 4 & 5\end{array}$

3. Whenever my coach tells me to do something as part of the team, he or she expects me to do it immediately without asking any questions.

$\begin{array}{lllll}1 & 2 & 3 & 4 & 5\end{array}$

4. As part of the team, once team policy is established, my coach discusses the reasoning behind the policy with the athletes on the team.

$\begin{array}{lllll}1 & 2 & 3 & 4 & 5\end{array}$

5. My coach always encourages verbal give-and-take whenever I feel that team rules and restrictions are unreasonable.

$\begin{array}{lllll}1 & 2 & 3 & 4 & 5\end{array}$

6. My coach always feels that what his or her athletes need is to be free to make up their own minds and do what they want to do, even if this does not agree with $\begin{array}{lllll}1 & 2 & 3 & 4 & 5\end{array}$ what their coaches might want. 
7. As part of the team, my coach does not allow me to question any decision he or she makes.

8. As part of the team, my coach directs the activities and decisions of the team members through reasoning and discipline.

$\begin{array}{lllll}1 & 2 & 3 & 4 & 5\end{array}$

9. My coach always feels that more force should be used by coaches in order to get their athletes to behave the way they are supposed to.

$\begin{array}{lllll}1 & 2 & 3 & 4 & 5\end{array}$

10. As part of the team, my coach does not feel that I need to obey rules and regulations of behavior simply

$\begin{array}{lllll}1 & 2 & 3 & 4 & 5\end{array}$ because someone in authority has established them.

11. As part of the team, I know what my coach expects of me, but I also feel free to discuss those expectations with my coach when I feel that they are unreasonable.

$\begin{array}{lllll}1 & 2 & 3 & 4 & 5\end{array}$

12. My coach feels that wise coaches should teach their athletes early just who is boss on the team.

$\begin{array}{lllll}1 & 2 & 3 & 4 & 5\end{array}$

13. On the team, my coach seldom gives me expectations and guidelines for my behavior.

$\begin{array}{lllll}1 & 2 & 3 & 4 & 5\end{array}$

14. Most of the time as part of the team my coach does what the athletes on the team want when making team decisions.

$\begin{array}{lllll}1 & 2 & 3 & 4 & 5\end{array}$

15. As the team members of the team playing together, my coach consistently gives us direction and guidance in rational and objective ways.

$\begin{array}{lllll}1 & 2 & 3 & 4 & 5\end{array}$

16. As part of the team, my coach gets very upset if I try to disagree with him or her. 
17. My coach feels that most problems on a team will be solved if coaches did not restrict their athletes' activities, decisions, and desires as they are playing on the team.

18. As part of the team, my coach lets me know what behavior he or she expects of me, and if I don't meet those expectations, he or she punishes me.

$\begin{array}{lllll}1 & 2 & 3 & 4 & 5\end{array}$

19. As part of the team, my coach allows me to decide most things for myself without a lot of direction from him or her.

$\begin{array}{lllll}1 & 2 & 3 & 4 & 5\end{array}$

20. As part of the team, my coach takes the athletes' opinions into consideration when making team decisions, but he or she will not decide for something simply because the athletes want it.

21. My coach does not view himself or herself as responsible for directing and guiding my behavior as part of the team.

22. My coach has clear standards of behavior for the athletes on our team, but he or she was willing to adjust those standards to the needs of each of the individual $\begin{array}{lllll}1 & 2 & 3 & 4 & 5\end{array}$ athletes on the team.

23. My coach gives me direction for my behavior and activities as part of the team and he or she expected me to follow his or her direction, but he or she is always willing to listen to my concerns and to discuss that direction with me.

24. As part of the team, my coach allows me to form my own point of view on team matters and he or she generally allows me to decide for myself what I am $\begin{array}{lllll}1 & 2 & 3 & 4 & 5\end{array}$ going to do. 
25. My coach always feels that most problems on the team would be solved if we could get coaches to strictly and forcibly deal with their athletes when they don't do what they are supposed to as part of the team.

26. As part of the team, my coach often tells me exactly what he or she wants me to do and how he or she expects me to do it.

$\begin{array}{lllll}1 & 2 & 3 & 4 & 5\end{array}$

27. As part of the team, my coach gives me clear direction for my sports related behaviors and activities, but he or she is also understanding when I disagree with him or her.

28. As part of the team, my coach does not direct the behaviors, activities, and desires of the athletes on the team.

29. As part of the team, I know what my coach expects of me and he or she insists that I conform to those expectations simply out of respect for his or her $\begin{array}{lllll}1 & 2 & 3 & 4 & 5\end{array}$ authority.

30. As part of the team, I my coach makes a decision on the team that hurts me, he or she is willing to discuss that decision with me and to admit it if he or she made $\begin{array}{lllll}1 & 2 & 3 & 4 & 5\end{array}$ a mistake. 